International Journal of Instruction e-ISSN: 1308-1470 • www.e-iji.net

Article submission code: 20210406133259

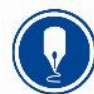

January $2022 \bullet$ Vol.15, No.1

p-ISSN: 1694-609X

pp. 1025-1044

Received: 06/04/2021

Revision: 01/09/2021
Accepted: 24/09/2021

OnlineFirst: 21/12/2021

\title{
Engagement with a Sequence of Feedback-Correction: A Case Study of Secondary School Students in Vietnam
}

\section{Trang Thi Doan Dang}

Dr., Faculty of Postgraduate Studies, Ho Chi Minh City Open University, Vietnam, trang.dtd@ou.edu.vn

\section{Janet Scull}

Assoc. Prof., Faculty of Education, Monash University, Australia, janet.scull@monash.edu

\section{Raqib Chowdhury}

Dr.,Faculty of Education, Monash University, Australia, raqib.chowdhury@monash.edu

\begin{abstract}
This exploratory study investigated Vietnamese secondary students' engagement in a sequence of detecting, correcting, and rewriting tasks, and examined the factors affecting their engagement and/or disengagement in the process. The study draws on the principles of task-based instruction, involving eight mixed-ability groups $(n=31)$, and was designed to address student engagement with feedbackcorrection practices that has rarely been discussed in previous research and has therefore remained largely underexplored, especially in the context of Vietnam. Theoretical concepts of behavioral, cognitive, and social engagement were used to analyze data from audio recordings of students' interactions and their written responses to open-ended questions. The analysis of data showed that the eight groups engaged behaviorally, socially, and cognitively in the process, although their engagement varied according to the learning tasks, the teacher's intervention, peer support, English ability, and types of gaps. Findings from the eight-week intervention suggest teachers should consider factors which determine student engagement with feedback-correction practices. By offering students opportunities to act on specific language issues in their writing through detecting and correcting gaps and rewriting the corrected texts, engagement with feedback-correction practices can be useful in fostering accuracy development. This qualitative multiple-case study contributes new insights to the field by operationalizing the sequence of feedback-correction through collaborative learning to deeply understand students' multidimensional engagement in the process from which implications for $\mathrm{L} 2$ writing and further research are discussed.
\end{abstract}

Keywords: engagement, sequence of correcting tasks, written corrective feedback, collaborative learning, student

Citation: Dang, T. T. D., Scull, J., \& Chowdhury, R. (2022). Engagement with a sequence of feedback-correction: A case study of secondary school students in Vietnam. International Journal of Instruction, 15(1), 1025-1044. https://doi.org/10.29333/iji.2022.15158a 


\section{INTRODUCTION}

Although the role of feedback has been long recognized in second language (L2) writing studies, student engagement with feedback still concerns teachers and researchers. Feedback to address incorrect forms of language in students' written texts - often termed written corrective feedback (WCF) in the L2 literature - involves direct and indirect correction. The former indicates a provision of direct correction of linguistic errors and/or explanations to the student, while the latter provides an indication of an error (Bitchener, 2018). The level of explicitness between direct and indirect methods may cause different levels of engagement with WCF, although recent research has mainly considered the forms of feedback that are the most useful (Storch, 2018). Thus, scholars have called for more empirical research into student engagement with classroom-based corrective feedback (CF) practice (Ferris, 2011; F. Hyland, 2010; Lee, 2013; Pawlak, 2014; Van Beuningen, 2010).

Given the general shift to learner-centred approaches in recent decades, scholars and teachers believe that students should learn to locate and work on their own gaps through teachers' feedback (Lee, 2009). This highlights the importance of engaging students with feedback-correction practices, as a key component in teaching writing. In L2 writing, engagement with feedback is considered "crucial for students' development" (Han \& Hyland, 2019, p. 247). However, to date, minimal research on feedback has focused on maximising students' engagement through sequencing correcting tasks. To address this, the study reported here draws on the principles of task-based language teaching (TBLT; Ellis, 2006) to design a sequence of detecting and correcting errors and rewriting practice that was operationalized by group work. In this paper, the sequence of correction is referred to as a correcting process. Further, grammatical errors and irrelevant forms of content are defined as 'gaps', correction as feedback and correction practices, and feedback as oral and/or written forms of comments. In particular, the correction in this study focused on the incorrect use of the simple present and past tense and conjunctions (because, although, but), and the use of topic sentences and the relevance of the ideas in supporting sentences in students' texts (letters and descriptions).

Data were collected from audio recordings and students' written responses to three open-ended questions. Integrating an exploratory case study into the experimental treatment, this classroom-based research provides evidence of students' behavioral, cognitive and social engagement with the correcting practices through their collaborative work with peers within intra-groups and among inter-groups.

\section{Literature Review \\ Engagement with Learning Tasks and Feedback}

Despite a wide range of definitions and various interpretations of the term, "engagement" is generally recognized as playing a crucial role in language learning. The focus of TBLT is to engage students in working on learning tasks (Harmer, 2007), which involve specific activities focusing primarily on meaning, with learners' use of their own ideas and language, working towards a clearly defined outcome (Ellis, 2006). 
According to Philp and Duchesne (2016), engagement in task-based instruction is referred to as "highlighted attention and involvement", regarding the dimensions of cognitive, behavioral, affective, and social engagement (p. 51). Behavioral engagement is described as being 'on task' or participating in tasks, while cognitive engagement refers to processes with indicators such as questioning, exchanging ideas, giving explanations and directions, and providing feedback or comments. Social engagement focuses on collaborating with peers to perform learning tasks; while affective engagement is an attitudinal aspect, for example, learners' attitude or willingness to participate in learning.

The term "engagement" is also related to feedback processes and practices. For example, engagement has been conceptualized in terms of the deep process of direct feedback (Qi \& Lapkin, 2001), while it is also associated with direct and indirect forms of feedback (Storch \& Wigglesworth, 2010), alongside monitoring and editing practices (Ferris, Liu, Sinha, \& Senna, 2013). Engagement has also been extended to correcting strategies that enhance the use of target structures in the revision process (F. Hyland, 2003). Similarly, Simard, Guénette, and Bergeron (2015) view engagement as a form of understanding of the teacher's corrections through students' verbal responses to both direct and indirect feedback. However, engagement with CF is affected by learners' language ability and motivation and contextual factors such as learning activities and contexts (Ellis, 2010). According to Ellis, engagement is related to learners' responses to the feedback provided to them. He ascribes to three aspects of engagementbehavioral, cognitive, and attitudinal. Behavioral engagement refers to learners' uptake of oral corrections or revision of written texts; cognitive engagement is related to "how learners attend to the CF they receive" (p. 342), and attitudinal engagement focuses on learners' affective responses (e.g., anxiety and dislike) to CF.

Aspects of engagement and WCF have been recently reported largely favouring undergraduate and graduate students. For example, Han and Hyland (2015) examined Chinese university students' cognitive, behavioral, and affective engagement with WCF and concluded that students' beliefs and their learning experiences and context resulted in differences in individuals' engagement. These authors also confirmed that the three dimensions of engagement are interrelated, corroborating findings of recent studies in higher education (Zheng et al., 2019; Yu \& Jiang, 2020). However, Zheng et al. (2019) clarify that Master students' behavioral engagement with supervisor feedback on thesis drafts was apparent and advise teachers to be also aware of students' affective and cognitive perspectives as these responses are important to learning outcomes. In contrast, Yu and Jiang (2020) confirm that although PhD students' affective engagement with feedback was affected by the nature of feedback and experience of the supervisor their affective and behavioural engagement varied.

Other studies have explored university students' multiple dimensions of engagement with feedback and how this is mediated by person-related, task-related, or strategyrelated beliefs (Han, 2017), by computer-generated feedback (Zhang, 2016), and by learners' proficiency levels (Zheng \& Yu, 2018). Han (2017) concluded that interaction and conflict between person-related, task-related, and strategy-related beliefs facilitate 
engagement with feedback. Zhang (2016) single case study confirmed that while student behavioral engagement was obscure, cognitive engagement was positive, and emotional attributes were affected by writing scores. In addition, research reports learners' lower level of English proficiency may have a negative impact on their cognitive and behavioral engagement with the teacher's WCF (Zheng \& Yu, 2018). While these studies have clarified dimensions of engagement with WCF, there has been little focus on students' engagement with a sequence of feedback and correction through collaborative learning.

\section{Dimensions of Engagement in the Present Study}

Drawing on extant research (Ellis, 2010; Philp \& Duchesne, 2016), the present study refers to engagement as students' responsive actions to or enactment of the sequence of correction as they worked in small groups to detect gaps, process the identified gaps, and rewrite the texts. The concept of behavioral engagement was considered through an examination of students' on-task performance, and participation in the three correcting phases as they worked in small groups. The cognitive dimension was explored as students processed and regulated gaps within and among groups; for instance, asking questions for clarification, giving suggestions, and providing reasons and/or explanations to respond to feedback/comments on their peers' work. The social concept was analyzed through an examination of how individuals, in and among groups, collaborated with peers to perform the correcting tasks; for example, listening to peers' feedback and ideas and providing feedback and directions to peers. The incorporation of the social dimension was necessary as the study investigates students' collaborative correction that entails social interactions. However, the affective dimension was excluded as attitudinal responses were not able to be analyzed from the data collected.

\section{Engagement with CF within the Guided Learning Framework}

Previous L2 literature has broadly proposed the potential for engaging students in feedback practice through the lens of guided learning. Teachers can mediate learning through offering meaningful, purposeful, and effective feedback practices to engage students in teacher-student interaction in process-oriented writing instruction (Lee, 2014). In Lee's view, research into feedback practices should investigate the ways English as a Foreign Language (EFL) teachers and students participate in transformational actions and their actual enactment of these in classroom activities. When students are assisted with correction, they may perform certain language functions that they are unable to enact independently, and thus CF is seen as a socially orientated process (Ellis, 2009, 2013; Erlam, Ellis, \& Batstone, 2013). Such interactive and collaborative correcting practice gradually assists students to solve gaps in their writing, learning to use language features appropriately, and modifying and developing their own ways of learning. However, this interactive practice is seen as a demanding process (Majer, 2003) for both teachers and learners. Although empirical studies have examined the effects of feedback through the expert-novice interaction to process gaps (Aljaafreh \& Lantolf, 1994; Erlam et al., 2013; Nassaji \& Swain, 2000; Rassaei, 2014), feedback was mainly provided via oral responses between a teacher and an individual student. This practice, however, has rarely been investigated in actual writing classrooms. 
From a pedagogical perspective, the effect of CF may be strengthened when situated within a supportive and interactive learning environment (Ur, 1996). When engaged in peer correction or group activities, learners are provided with opportunities to argue, explain, clarify, negotiate, and scaffold each other's learning (Storch, 2001). These aspects of learning are useful for promoting learner autonomy and critical thinking (Yang, Badger, \& Yu, 2006) and can build various forms of cognitive and social learning (K. Hyland, 2009). Such collaborative correcting practices may also foster students' independent learning and thinking, negotiating, and scaffolding skills, while also providing additional support for students who are struggling to notice and correct gaps in their writing (Qi \& Lapkin, 2001).

While previous studies have informed the current study, no research to our knowledge has examined the dimensions of engagement with a sequence of feedback and correction. To address students' limited engagement with $\mathrm{CF}$, not only has the correcting design been sequenced with levels of difficulty but also conducted through group-based learning.

\section{METHOD}

\section{Research Design}

As part of a larger study about student engagement with feedback and correction practices, this study explored students' engagement with the correcting sequence and factors affecting their engagement and/or disengagement. The exploratory approach was integrated into the correcting treatment to gain a deeper understanding of students' behavioral, cognitive, and social dimensions of engagement through teacher-student and student-student interactions. The enquiry used data from audio recordings and students' written responses to open-ended questions to provide insights into students' dimensions of engagement across learning tasks with multiple levels of difficulty, which were designed to facilitate student engagement. Specifically, this study examined the following research questions.

1. How did the eight student groups engage with the sequence of feedback and correction?

2. What factors affected their engagement and/or disengagement with the correcting sequence?

\section{Context and Participants}

The study was conducted at a large government secondary school in Ho Chi Minh City, Vietnam. At this school, students learn English as a compulsory subject and use English textbook where TBLT is the intended methodology (Hoang, Hoang, Do, \& Nguyen, 2006). Recent reforms in English language teaching (ELT) encouraged teachers to engage students in the learning process, with a particular focus on listening, speaking, reading, and writing skills in line with the national English curriculum. Despite this, ELT has largely been influenced by local exam-based approaches, which exclude listening, speaking, and writing skills. 
The pressure of school tests and exams that preclude any significant development in students' writing skills has failed to involve students in feedback and correction practices. While teachers are expected to help students produce effective pieces of writing, there are neither specific guidelines in the teacher's guide book nor time allocated for correcting practices. When assessing students' written texts, teachers often devote considerable time after class in providing correct forms of erroneous structures or indicating incorrect use of language and/or ideas on students' writing. This provides an impetus for conducting the present research into engagement with feedback and correction practices.

The participants were 31 Year 10 senior secondary students aged 16 (females $n=14$; males $n=17$ ) who started learning English in year 6. Their English is at a lowintermediate level, and they were representative students in the Science stream with the three main subjects Mathematics, Physics, and Chemistry. These students match the typical larger populations across the country as English is not their major subject. As the focus was on a peer tutoring learning environment, students were purposefully divided into eight mixed-ability groups (Groups 1-8) based on their English scores in the firstsemester exam. Their scores ranging from 3.0-4.75, 5.0-6.75, 7.0-8.75 to 9.0-10 points are described as below fair, fair, good, and excellent levels.

\section{Treatment Procedure}

Over a period of eight weeks, participating students were first instructed to write on eight different topics in their morning class, which were followed by the correcting sessions in the afternoon. Six topics were from the English textbook (Hoang et al., 2006) while two were picture descriptions adopted from Ur (2009). These included a letter detailing past memorable activities, an invitation, a letter of acceptance, a letter of complaint, a description of one of the most popular events or celebrations in Vietnam, and the topics of a 'favorite school', 'the boy and the wallet', and 'the fox and the grapes'. The eight groups of students worked on the same eight written outputs that were selected based on the three categories of gaps (see Appendix B) and were anonymous. The purpose of anonymity is for the student writers not to feel uneasy when their papers were overtly treated.

The three phases of correction incorporated the sequence of a task-based lesson; the pretask phase: detecting gaps; the during-task phase: processing/treating gaps; and the posttask phase: the rewriting practice. These tasks emphasized aspects of learning by detecting and doing, which aimed to raise students' awareness of specific kinds of gaps via multiple levels of engagement with feedback and correction practices.

A non-native English teacher holding a master's degree in TESOL administered the three phases of correction. The teacher (not the researcher) first delivered copies of the written texts selected to the eight groups of students and instructed them to use the feedback guide to discover the three kinds of gaps in peers' texts. As a facilitator, the teacher not only observed and interfered in group-work to provide feedback and instruction when groups had learning difficulties but also prompted feedback and corrections from peers across groups (inter-peers). For example, if the gaps could not be identified, the teacher used indirect feedback or questions to help students locate the 
unidentified gaps. Students then worked together with peers within/intra-groups to treat the gaps detected. Following this, the students presented and shared their corrections with other groups, which aimed to promote students' ability to proofread peers' corrections, give and respond to feedback, and ask for clarification. Finally, students practiced rewriting the corrected texts within groups, compared the rewritten texts with the original ones, and shared their revised texts with other groups. Overall, not only did students receive support from peers within groups and from the teacher to complete the learning tasks, but they also provided and responded to inter-peers' feedback through groups' presentation and/or transforming practice after each phase of correction.

\section{Data Collection and Analysis}

The collection of data took place over an eight-week period following the gaining of consent from students and their parents. The researcher acted as a participant, observing, and taking notes on the eight groups' learning performance. As the researcher could not track all eight groups' learning activities and responses, each group's performance and presentations were audio recorded. This paper reports excerpts of the different groups to demonstrate evidence of the students processing different types of gaps and a range of engagement within/among groups and groups and the teacher.

The three open-ended questions elicited the eight groups' responses after experiencing each correcting session. The first question focused on students' thoughts about the correcting sequence while the second question emphasized individuals' engagement in each phase, and the final question collected students' reflections on each phase. These questions were used to check the relevance of the correcting sequence and individuals' engagement within each group, to validate the observational data, and to minimize the researcher's subjectivity. The written responses of each group relevant to individuals' engagement were used to expand on the excerpts of the observational data.

The analysis of data involved inductive and deductive approaches. The researcher first transcribed the audio recordings of each group, read, checked, and classified the transcripts according to themes. Next, themes were identified and linked and compared to the students' written responses to the three open-ended questions. Then, a deductive approach was adopted; a summary table was prepared to code the data with the theoretical concepts of engagement (see Appendix A).

\section{FINDINGS}

The two research questions explored how the eight student groups engaged with the correcting sequence and factors affecting their engagement and/or disengagement.

The analysis showed the eight groups' different levels of behavioral, cognitive, and social engagement. While Groups 1, 3, 5 and 8 had fully engaged participants, Groups 2 and 7 had partially engaged participants, and Groups 4 and 6 received support from the teacher and peers to engage in the process. Group engagement was categorized into five main themes: full engagement with intra-group correction, full engagement with intergroup correction and revision, partial engagement with intra-group discovery and revision, external support for engagement with intra-group correction, and limited 
engagement with discovering and rewriting tasks. The correcting tasks, group-work, types of feedback and gaps, first language, and the teacher's intervention were all seen to have affected students' engagement. These factors are used to account for levels of engagement of the eight groups that are presented below.

\section{Full Engagement with Intra-group Correction}

The following conversation shows an example of full engagement. When students (S) in Group 8 interacted with each other to find appropriate solutions for treating grammatical errors, they behaviorally (BEH), socially (SOC), and cognitively (COG) engaged to process gaps. Transcript 1 below shows the way students in Group 8 (using both English and Vietnamese) worked to replace "and" with "but" in the eighth correcting session.

\section{Transcript 1}

1. S1: Do you see this sentence [is] wrong? ${ }^{\mathrm{SOC}}$

2. S2: What ...? The classroom has [an] air-conditioner and it does not work. ${ }^{\mathrm{BEH}} \mathrm{I}$ am not sure.

3. S1: Can we use and? ${ }^{\mathrm{COG}}$

4. S3: And is wrong because ... ${ }^{\mathrm{BEH}}$

5. S2: Because what? ${ }^{\text {SOC }}$

6. S3: Don't know ..., có thể là do [it's probably because] “it doesn't work”COG

7. S1: "It doesn't work ..., it doesn't work ..." à trái nghĩa với câu đầu... dùng ... but [Ah, opposite meaning with the first sentence, ... use ... but $]^{\mathrm{COG}}$

8. S3: Let's see ... the classroom has [an] air-conditioner but it doesn't work ... ok. ${ }^{\mathrm{BEH}}$ What do you think Ai? ${ }^{\text {SOC }}$

9. S4 (Ai): The classroom has [an] air-conditioner but it doesn't work ..., seem okay, ${ }^{\mathrm{BEH}}$ but not sure.

10. S1: The classroom has [an] air-conditioner but it doesn't work, correct. ${ }^{\mathrm{BEH}}$

The exchange in Transcript 1 shows clear evidence of behavioral, cognitive, and social engagement in correcting the conjunction "and" by replacing it with "but". While S1, S2, S3 attended to treating the gaps and worked on the correcting tasks to fully understand their corrections, S4 only responded to peer's question by repeating the sentence and stating "seem okay" (line 9). In particular, in lines 1 and 3, S1 raised the question stating that "and" in the sentence is incorrect, and S2 and S4 (lines 2 and 9) attempted to behaviorally engage in the correcting task by repeating the sentences, and $\mathrm{S} 3$ confirmed that "and is wrong" without an explanation in line 4 . Then, cognitive engagement appears when S3 provided a possibility in line 6 and S1 suggested using "but" through repeating the sentence to recall previous grammatical knowledge. In lines 8 and 9, S3 and S4 socially and behaviorally engaged with the correcting task by asking peer's ideas, repeating the sentence, and confirming the correction "okay", although they appeared to be unsure. S1 again repeated the sentence and confirmed it as correct in line 10. This example clearly shows that indirect feedback (asking questions) and repetition are signs of promoting behavioral, cognitive, and social engagement as the students worked out the correct use of "but". In this case, the students (except S4) were active respondents to linguistic errors and feedback providers in their group work. The transcript indicates the interrelatedness of behavioral, cognitive, and social dimensions 
of engagement and supports the claim that a single dimension of engagement with $\mathrm{CF}$ may be insufficient for productive learning (Ellis, 2010; Han \& Hyland, 2015).

\section{Full Engagement with Inter-group Correction and Revision}

The following exchange in Transcript 2 provides an example of joint practice between inter-peers (peers across groups) and the teacher (T). Group 5 received indirect feedback and direct cues on the grammatical error "because" from peers outside of their group and the teacher when they presented their corrected text.

\section{Transcript 2}

1. S1: Why don't you combine the sentences in paragraph 2 "And the water was splashed all my teacher body. His body was all wet"soc.

2. S2: How? ${ }^{\text {SOC }}$

3. S1: Use "because"COG

4. S2: Okay, let's try ... his body was all wet because the water was splashed. ${ }^{\mathrm{COG}}$

5. S3: Is it correct? ${ }^{\text {SOC }}$

6. S2: Not sure, but ... ${ }^{\mathrm{BEH}}$

7. S3: It should be "my teacher['s] body was all wet because the water was splashed". ${ }^{\mathrm{COG}}$

8. S4: It's ok now. ${ }^{\text {BEH }}$

9. T: Good! You know to use because to combine the two sentences, but there are still errors, double check it.

10. S5: Can we change the verb active? ${ }^{\text {SOC }}$

11. T: Read your sentence

12. S5: My teacher['s] body was all wet because the guys splashed the water. ${ }^{\text {COG }}$

13. T: Is it correct class? My teacher body was all wet because the guys splashed the water.

14: S6: My teacher's body was all wet because the guys splashed the water. ${ }^{\text {COG }}$

15: T: That's fine, but this sentence is better "my teacher was wet because the guys splashed the water on his body."

16. S5: That's why we need you, teacher.

This example indicates that the teacher's intervention, peer support, indirect feedback, and direct clues are factors that promoted students' behavioral, cognitive, and social dimensions of engagement. Here, social engagement emerges when S1 in line 1 raised a question (indirect feedback) that encouraged S2 to combine the two sentences, although S2 showed she was unable to do it immediately when she asked "how" in line 2. In line 3 , S1 cognitively engaged in the correcting task by suggesting using "because" to assist $\mathrm{S} 2$ to combine the sentences in line 4 . In this case, although $\mathrm{S} 2$ was unable to provide a completely correct sentence, she was able to use "because" to link the two sentences as suggested by S1. The students' responsive actions (lines 5, 7, 8, 10, 12, and 14) exhibit the three dimensions of engagement when searching for an appropriate form of using "because" to combine the two sentences, through peer support and comments. This highlights the important role of experts' guidance (i.e., teacher and advanced peers), without which students were unable to perform independently. While this finding 
elaborates the claim that direct and indirect feedback is associated with student engagement (Storch \& Wigglesworth, 2010), it values guided learning, in which the teacher and peers are agents who facilitate engagement.

In another case, students' behavioral, social, and cognitive engagement with rewriting resulted in a comprehensible text (see Appendix $C$ ). When Group's 8 presented their rewritten text, they received inter-peers' feedback on remaining errors. The following exchange between one member of Group (G) 1 and Group 8 shows that all three dimensions of engagement are connected.

\section{Transcript 3}

G1: Your revision is good. You added a topic sentence in the second paragraph and reordered some sentences. ${ }^{\text {BEH }}$ Why [did] you still keep 'passive voice' in the first sentence of the last paragraph 'I hope you enjoy the story I had been told to you'?

G8: Thanks 'I hope you enjoy the story I had been told you'. Oh, no, it's 'I hope you enjoy the story I have told you'. ${ }^{\mathrm{COG}}$ Is it ok? ${ }^{\text {SOC }}$

G1: Yes, excellent!

The above conversation reveals support and feedback provided that enabled Group 8 to rewrite the text. Their rewritten text improved as they added the topic sentence and corrected errors related to tenses, although they did not address the incorrect use passive voice. This example indicates that presenting the rewritten text triggered behavioural and social engagement while peer feedback facilitated cognitive engagement. This suggests that peer feedback is useful for both checking and improving accuracy.

\section{Partial Engagement with Intra-group Discovery and Revision}

Signs of partial engagement were also observed and recorded. Group 2's written responses after the third and the eighth correcting sessions showed evidence of unequal contributions to group-work: "two individuals did not participate in discovering gaps", "one member hesitated to discover gaps, and we had to remind him". Although this shows that some students did not behaviorally engage in the task, the act of reminding peers reinforced the sense of belonging to a group. In addition, it was noted that not all members of Groups 2 and 7 engaged with rewriting the texts. Group 7, for example, reported "we cannot collaborate well to rewrite the text" and "two members did not participate well in the rewriting task". Students' responses showed that members of their groups did not fully engage with rewriting the texts. This suggests that either the rewriting task challenged learners with a low level of English, or students lacked the motivation to rewrite the text. This finding supports the claim that differentiated aspects such as learning ability and motivation may affect the extent to which learners engage in CF (Ellis, 2010).

\section{External Support for Engagement with Intra-group Correction}

The analysis also showed that Groups 4 and 6 required support from their peers and the teacher to perform the tasks. These two groups completed the correcting and rewriting tasks with external support as they asked questions and called for help from the teacher and peers, as evidence of social engagement. Group's 4 written responses showed "We 
received more assistance from the teacher to make the topic sentence relevant to the developing ideas", which resulted in them completing their corrections. In contrast, although the students of Group 6 were responsive to the instruction, they were uncertain of their corrections, especially when they were revising the topic sentence to make it relevant to the supporting sentences. Thus, their engagement was evidence of, and responsive to, both the teacher's assistance and peers' collaboration. Transcript 5 shows the exchanges between individuals in Group 6 and the teacher (using both Vietnamese and English).

Transcript 5

1. S1: I don't understand this. ${ }^{\text {BEH }}$

2. S2: Look! We need to say reasons to complain. ${ }^{\text {SOC }}$

3. S1: Còn câu [the sentence] "I'm writing to complain about the poor quality of the services at your center" để làm gì [used for]? ?OC $^{\mathrm{SOC}}$

4. S2: Hỏi cô đi [Ask the teacher] ... Please explain this, teacher! ... Nam hỏi 'câu này để làm gì?' [Nam asks 'what is this sentence used for?'] ${ }^{\mathrm{SOC}}$

5. T: Mình dùng nó để mở đầu cho lá thu complaint [We use this as an opening of the letter of complaint]. Ở đoạn 2 trước nội dung em complain, em nên dùng 1 câu topic [In the second paragraph, before the contents of your complaint, you should use a topic sentence]. Em giải thích thêm về câu topic cho bạn giúp cô nhe [Help me explain more about the topic sentence]

6. S2: Mình cần sứa câu topic cho rõ nghĩa hơn [We need to correct the topic sentence to make it more meaningful] $]^{\mathrm{SOC}}$

7. S1: Sưa thế nào? [How?] ${ }^{\mathrm{SOC}}$

8. S2: Cho ý kiến đi Linh [Your ideas, Linh?] ${ }^{\mathrm{SOC}}$

9. S3: Ammm ... Tó chỉ biết thay tù learning bằng facility và thêm vào are not good [I just know to replace learning with facility and add are not good] ${ }^{\mathrm{COG}}$

10. S2: Vậy câu của nhóm mình là the facility and teaching quality are not good. [Thus, our group's sentence is the facility ... good]. ${ }^{\mathrm{COG}}$ Mình chờ xem các nhóm khác sữa thế nào rồi mình chỉnh lại sau [We wait for other groups to correct this, then we revise it later].

Transcript 5 indicates that indirect feedback, peer support, the types of error, and learners' first language (L1) all promote behavioral, cognitive, and social engagement. In line 1, S1 was not sure about the topic sentence, and S2 used indirect feedback in L2 with cues to motivate her peers to think about the issue. Then, in line 3, S1 switched from English to Vietnamese to gain a clear meaning while the teacher (line 5) used Vietnamese to direct students' attention to a missing topic sentence, and then asked another student (S2) to support peers. Furthermore, a nongrammatical gap (irrelevant topic sentence) called for more engagement and further contributions with a shift from indirect to direct types of delivery. For instance, $S 2$ in line 6 asked her peers to amend the meaning of the topic sentence, and then S1 (line 7) raised the question of how to correct the sentence. To respond to S1's question, S2 (line 8) asked for S3's ideas. Consequently, an explicit answer was provided (line 9); however, S3 stated that "I just know to replace ...". S2 (line 10) confirming the answer by repeating the sentence suggested by S3, while at the same time stating the need to wait for the other groups' 
corrections. This example (Transcript 5) illustrates how the nongrammatical gap prompted aspects of social and cognitive engagement and interactions moving from the provision of indirect feedback to direct feedback; yet this also resulted in a degree of uncertainty as students worked to resolve the gap.

\section{Limited Engagement with Discovering and Rewriting Tasks}

However, social and behavioral engagement when detecting the gaps does not necessarily result in understanding. In the following example, Group 3 failed to provide clear explanations as to why the underlined words or phrases were incorrect (including the problem with the first preposition) to respond to Group 1's question although they could identify the incorrect use of the simple past tense. This finding corroborates evidence that interactions and language ability may affect engagement with feedback (Han, 2017; Zheng \& Yu, 2018) and suggests that students' low English levels might have prevented them from explaining the identified gap. Consider the following exchanges in Transcript 4 between students in Groups (G) 1 and 3.

\section{Transcript 4}

G1: why [did] you underline the sentence "while I walked on the swimming pool, some of my friends pushed me into the water"? $\mathrm{SOC}$

G3: uhum ..., we just realize that it is incorrect, ${ }^{\mathrm{BEH}}$ we don't know why.

Similarly, students from Group 1 also faced difficulties in explaining the identified gaps. Although the students attempted to respond to comments provided by their peers, they were unable to provide clear explanations for the lack of congruence between the topic sentence and the supporting ideas. A student from Group 1 reported, "We could identify some gaps but we are not quite sure why they are incorrect or to explain them". This finding suggests that providing explanations for the gaps identified was beyond the level of ability of some students. Behavioral and social engagement in this task shows the level of noticing, rather than understanding required for a greater depth of processing a subcategory of cognitive engagement with WCF (Han \& Hyland, 2015).

Although Group 8 voluntarily presented their rewritten texts, provided feedback on inter-peers' revision, and offered assistance to inter-groups, this group responded to the open-ended question by stating they "faced difficulties rewriting the texts". Similarly, Group 1 reported "We found that rewriting is more difficult than discovering and correcting tasks". Students' responses demonstrate that their engagement with rewriting the texts was to a certain extent limited, which aligns with Ellis's (2010) assertion that learning activities may affect student engagement.

\section{DISCUSSION}

The study yields new insights into engaging groups of students in the sequence of correction through which multiple dimensions of engagement with feedback were explored. Importantly, engagement was varied with this influenced by the learning tasks, peers' collaboration, types of feedback and gaps, and students' L1 and English ability.

From a pedagogical perspective, while the sequencing tasks activate students' behavioral, social, and cognitive engagement, the engagement of groups can vary. 
Students clearly dealt with detecting and correcting tasks behaviorally, cognitively, and socially as they worked together with peers in intra-groups to locate and process the gaps. They also responded to inter-group peers' feedback to explain their detection and correction of gaps. While the difficulty of the rewriting task might, on the one hand, deter some students' engagement or motivation, but on the other, it may also trigger further collaboration, discussion, and negotiation in completing the rewritten text (Appendix C). This explanation finds support from Mariani (1997), who proposed the need for "high challenge" and "high support" to scaffold students' learning and motivate their autonomy (p. 10). Although behaviorally and socially engaging in detecting and correcting gaps did not result in complete explanations of Groups 1 and 3, it does highlight that learning by detecting and correcting gaps and rewriting texts can maximize students' engagement.

From the cognitive and social perspective, group-based learning might also maximize multidimensional engagement, whereby a variety of opportunities arise that in turn lead to effective learning. Experiencing intra- and inter-groups collaboration contributed to learners' awareness of using language, as shown in their negotiating, discussing, reasoning, scaffolding, commenting, and presentation of texts (Storch, 2001). These learning features may build a strong foundation for developing students' cognition and social skills in learning (Fisher, 2005; K. Hyland, 2009). Examples of providing and responding to peer feedback within such group-based correcting practice provide evidence that knowledge is refined through collaborative and active engagement in negotiating to detect and process gaps and rewrite texts. This substantiates evidence of a recent study reporting that peer feedback has resulted in students' higher level of revisions to their written texts (Hentasmaka \& Cahyono, 2021) and writing performance (Kusumaningrum, Cahyono, \& Prayogo, 2019). This can be understood through sociocultural theories that emphasize that knowledge is constituted through an interactive process in which individuals perform learning tasks with support from the teacher and advanced peers that they are unable to accomplish by themselves (Vygotsky, 1978, 1987). Thus, this finding prompts similar practices of empowering students' capability to learn from and teach others within/among mixed-ability groups (Fisher, 2005).

The teacher's indirect feedback and direct cues are also offered as possible mechanisms for triggering levels of engagement. From the cognitive perspective, indirect feedback involved students in cognitive processes, such as asking for clearer information, and providing and responding to feedback to problem-solve solutions. These opportunities led to an increased frequency of engagement, although a lack understanding of language features prevented Groups 1 and 3 from explaining their detection and correction and disengaged S2. This suggests that although indirect feedback could engage students in locating and processing gaps, they need to be linguistically proficient to participate effectively, as reported by recent research (Zheng \& Yu, 2018). Examples from this study provide evidence that indirect $\mathrm{CF}$ engaged students in cognitive processes to problem solve the incorrect forms of language (Ferris, 2011). The results strongly support processes of indirect and less-direct CF that provide opportunities for deeper cognitive processes (Enginarlar, 1993; Ferris, 2003, 2006; Westmacott, 2017). 
In addition, the use of L1 appeared to have promoted dimensions of engagement. Behavioral and social dimensions of engagement were seen as students code switched from English to Vietnamese to explain difficult issues, confirm information, and ask for further information, as shown in Transcripts 1 and 4 . These examples indicated that using L1 maintained dimensions of engagement and interaction and helped to clarify information. This highlights the key role of mediated learning experiences on the quality of interaction, regardless of what language is used (Feuerstein, 1990) and clarifies the importance of using L1 to minimize confusion and motivate students' engagement in learning corrections in EFL writing classrooms.

It is interesting to note that students' engagement in detecting and correcting tasks varied between grammatical and nongrammatical issues. Grammatical gaps were seen to activate students' behavioral, cognitive, and social engagement — as attested by the cases of correcting "but" intra-group (Group 8) and "because" inter-group (Group 5 and interpeers). Correcting these gaps appeared to increase the level of confidence and achievement. In contrast, amending nongrammatical issues such as the topic and supporting sentences required the teacher's assistance and greater levels of peers' collaboration; but it was also a possible cause for disengagement in some cases, such as in Groups 4 and 6. The challenge of correcting nongrammatical gaps was a possible explanation for varying levels of cognitive and social dimensions of engagement. The variation in learners' engagement in treating nongrammatical issues provides explanations for targeting specific types of gaps and including both treatable and untreatable categories (Ferris, 2006). The finding corroborates previous research reporting that a limited level of English has deterred students' behavioral and cognitive engagement (Zheng \& Yu, 2018), but it also illustrates that nongrammatical gaps might also account for levels of engagement.

\section{CONCLUSION}

The present study advances knowledge in L2 writing instruction and research data. It contributes new knowledge to the field by operationalizing the three phases of correction via group work and yielding an in-depth understanding of behavioral, cognitive, and social engagement with feedback and correction practices in an EFL writing context. The findings show that feedback and support from the teacher and peers are essential for fostering students' behavoural and social engagement to process gaps - an example of cognitive engagement. This study shows that all the three dimensions of engagement are interrelated and affect each other. However, in some cases behavioral and social engagement in discovering language issues did not necessarily result in high levels of understanding - a subcategory of cognitive engagement (Han \& Hyland, 2015) as students could not provide explanations for the gaps detected to respond to peer feedback.

The study also extends previous feedback research by designing the three phases of correction and incorporating social engagement via peer collaboration into the enquiry to provide a more complex picture of the different dimensions of engagement with feedback. It has also expanded knowledge about engagement with feedback by 
exploring how the eight student groups engaged with the sequence of feedbackcorrection and what factors determined their engagement and/or disengagement.

The correcting design, as informed by principles of TBLT, has pedagogical implications. Teachers should operationalize the design within a collaborative and scaffolded learning environment, with considerations of learning tasks and students' language ability to maximize students' multidimensional engagement with feedback. This model offers practical implications beyond the examination of students' engagement with feedback as it scaffolds learning so that students can move learning forward. Our research's conceptualisation as well as its empirical evidence of multidimensional engagement could also help teachers plan their scaffolding and feedback strategies to facilitate students' responsive actions to specific gaps in their writing. This study's findings suggest that group work is useful for engaging students with interactive and collaborative correcting practices that are associated with pedagogical values of motivation and retention as students learn by doing and reasoning. The shared construction of knowledge helped trigger behavioural, cognitive, and social engagement as students acted on, thought of, discussed, and explained ways to correct gaps with their peers.

However, the study has some limitations. As the eight groups were in one class of 31 students, the findings obviously cannot readily be generalised to other groups of students. Hence, further research on the correcting sequence with students with different levels of English proficiency from different educational contexts will be of interest. To elaborate on the findings, research combining different forms of feedback is also suggested. As explained, students could amend their written corrections and revisions based on the teacher's and peers' oral feedback through their presentations. Research that examines a combination of written correction and oral feedback and the impact of metalinguistic feedback within the correcting sequence on students' writing accuracy and engagement with writing tasks is therefore proposed to extend and build on the findings from this study. As our study addressed only how and why students engaged in the process, this sets an agenda for future research that examines multiple feedback methods to deeply understand students' perceptions and participation in the engagement in the feedback-correction process.

\section{ACKNOWLEDGEMENTS}

The study reported in this article was funded by Monash International Postgraduate Research Scholarship, Monash Graduate Scholarship, and Monash Postgraduate Publications Award. The authors sincerely thank Monash University for the financial support during the $\mathrm{PhD}$ study of the first author. We would also like to extend our special thanks to the participants of this study.

\section{REFERENCES}

Aljaafreh, A., \& Lantolf, J. (1994). Negative feedback as regulation and second language learning in the zone of proximal development. The Modern Language Journal, 78(4), 465-483. doi:10.2307/328585 
Bitchener, J. (2018). Direct versus indirect grammar feedback. In J. Liontas, I. (Ed.), The TESOL Encyclopedia of English Language Teaching (pp. 1-8). doi:10.1002/9781118784235.eelt0055

Dang, T. D. T. (2019). EFL learners' engagement in a socially mediated correcting sequence: Writing development and attitudes [Unpublished doctoral thesis, Monash University]. Australia.

Ellis, R. (2006). The methodology of task-based teaching. In P. Robertson \& J. Jung (Eds.), Special conference proceedings volume: Task-based learning in the Asian context (pp. 19-45). British Virgin Islands: Asian EFL Journal Press.

Ellis, R. (2009). Corrective feedback and teacher development. L2 Journal, 1, 3-18.

Ellis, R. (2010). Epilogue: A framework for investigating oral and written corrective feedback. Studies in Second Language Acquisition, 32(2), 335-349. doi:10.1017/S0272263109990544

Ellis, R. (2013). Corrective feedback in teacher guides and SLA. Iranian Journal of Language Teaching Research, 1(3), 1-18. https://eric.ed.gov/?id=EJ1127401

Enginarlar, H. (1993). Student response to teacher feedback in EFL writing. System, 21(2), 193-204. https://doi.org/10.1016/0346-251X(93)90041-E

Erlam, R., Ellis, R., \& Batstone, R. (2013). Oral corrective feedback on L2 writing: Two $\begin{array}{llll}\text { approaches } \quad \text { compared. } & \text { System, } & \text { 41(2), }\end{array}$ https://doi.org/10.1016/j.system.2013.03.004

Ferris, D. (2003). Response to student writing: Implications for second language students. Mahwah, N.J.: Lawrence Erlbaum Associates.

Ferris, D. (2006). Does error feedback help student writers? New evidence on the shortand long-term effects of written error correction. In K. Hyland \& F. Hyland (Eds.), Feedback in second language writing (pp. 81-104). Cambridge: Cambridge University Press.

Ferris, D. (2011). Treatment of error in second language student writing. United States of America: University of Michigan.

Ferris, D., Liu, H., Sinha, A., \& Senna, M. (2013). Written corrective feedback for individual L2 writers. Journal of Second Language Writing, 22(3), 307-329. http://dx.doi.org/10.1016/j.jslw.2012.09.009

Feuerstein, R. (1990). The theory of structural cognitive modifiability. In R. J. Presseisen, K. F. Sternberg, \& R. F. C. Knight (Eds.), Learning and thinking styles: Classroom interaction (pp. 68-134). Washington, DC: National Education Association.

Fisher, R. (2005). Teaching children to think. United Kingdom: Stanley Thornes. 
Han, Y. (2017). Mediating and being mediated: Learner beliefs and learner engagement with written corrective feedback. System, 69, 133-142. https://doi.org/10.1016/j.system.2017.07.003

Han, Y., \& Hyland, F. (2019). Learner engagement with written feedback: A sociocognitive perspective. In K. Hyland \& F. Hyland (Eds.), Feedback in second language writing: Contexts and issues (2 ed., pp. 247-264): Cambridge University Press.

Han, Y., \& Hyland, F. (2015). Exploring learner engagement with written corrective feedback in a Chinese tertiary EFL classroom. Journal of Second Language Writing, 30(Supplement C), 31-44. https://doi.org/10.1016/j.jslw.2015.08.002

Harmer, J. (2007). How to teach English. Harlow: Pearson Longman.

Hentasmaka, D. \& Cahyono, B. Y. (2021). Peer feedback uptakes and outcomes across EFL students' proficiency levels: A study at tertiary education in Indonesia. International Journal of Instruction, 14(3), 271-286. https://doi.org/10.29333/iji.2021.14316a

Hoang, V. V., Hoang, T. X. H., Do, T. M., \& Nguyen, Q. T. (2006). Tieng Anh 10 [English 10]. Hanoi: Education Publishing House.

Hyland, F. (2003). Focusing on form: Student engagement with teacher feedback. System, 31(2), 217-230. http://dx.doi.org/10.1016/S0346-251X(03)00021-6

Hyland, F. (2010). Future directions in feedback on second language writing: Overview and research agenda. International Journal of English Studies, 10(2), 171-182. https://search-proquest-

com.ezproxy.lib.monash.edu.au/docview/865733873? accountid=12528

Hyland, K. (2009). Teaching and researching writing. United Kingdom: Longman.

Kusumaningrum, S. R., Cahyono, B. Y. \& Prayogo, J. A. (2019). The effect of different types of peer feedback provision on EFL students' writing performance. International Journal of Instruction, 12(1), 213-224. https://doi.org/10.29333/iji.2019.12114a

Lee, I. (2009). Ten mismatches between teachers' beliefs and written feedback practice. ELT Journal, 63(1), 13-22. doi:10.1093/elt/ccn010

Lee, I. (2013). Research into practice: Written corrective feedback. Language Teaching, 46(1), 108-119. doi:10.1017/S0261444812000390

Lee, I. (2014). Revisiting teacher feedback in EFL writing from sociocultural perspectives. TESOL Quarterly, 48(1), 201-213. doi:10.1002/tesq.153

Majer, J. (2003). Interactive discourse in the foreign language classroom. Wydawn: Uniwersytetu Łódzkiego.

Mariani, L. (1997). Teacher support and teacher challenge in promoting learner $\begin{array}{llr}\text { autonomy. } & \text { Perspectives, } & \text { 5-19. }\end{array}$ http://www.learningpaths.org/papers/papersupport.htm 
Nassaji, H., \& Swain, M. (2000). A Vygotskian perspective on corrective feedback in L2: The effect of random versus negotiated help on the learning of English articles. Language Awareness, 9(1), 34-51. doi:10.1080/09658410008667135

Pawlak, M. (2014). Error correction in the foreign language classroom: Reconsidering the issues. New York: Springer.

Philp, J., \& Duchesne, S. (2016). Exploring engagement in tasks in the language classroom. Anпиal Review of Applied Linguistics, 36, 50-72. doi:10.1017/S0267190515000094

Qi, D. S., \& Lapkin, S. (2001). Exploring the role of noticing in a three-stage second language writing task. Journal of Second Langauge Writing, 10 (4), 277-303.

Rassaei, E. (2014). Scaffolded feedback, recasts, and L2 development: A sociocultural perspective. Modern Language Journal, 98(1), 417-431. doi:10.1111/j.15404781.2014.12060.x

Simard, D., Guénette, D., \& Bergeron, A. (2015). L2 learners' interpretation and understanding of written corrective feedback: Insights from their metalinguistic reflections. Language Awareness, 24(3), 233-254. doi:10.1080/09658416.2015.1076432

Storch, N. (2001). How collaborative is pair work? ESL tertiary students composing in pairs. Language Teaching Research, 5(1), 29-53. http://ezproxy.lib.monash.edu.au/login?url=http://search.ebscohost.com/login.aspx?dire ct=true \&db=ufh\&AN=7392422\&site=ehost-live \&scope $=$ site

Storch, N. (2018). Written corrective feedback from sociocultural theoretical perspectives: A research agenda. Language Teaching, 51, 262-277. doi:10.1017/S0261444818000034

Storch, N., \& Wigglesworth, G. (2010). Students' engagement with feedback on writing: The role of learner agency/beliefs. In R. Batstone (Ed.), Sociocognitive perspectives on language use and language learning (pp. 166-185). Oxford: Oxford University Press.

Ur, P. (1996). A course in language teaching: Practice and theory. New York: Cambridge University Press.

Ur, P. (2009). Grammar practice activities: A practical guide for teachers. New York: Cambridge University Press.

Van Beuningen, C. (2010). Corrective feedback in L2 writing: Theoretical perspectives, empirical insights, and future directions. International Journal of English Studies, 10(2), 1-27. doi:10.6018/ijes/2010/2/119171

Vygotsky, L. (1978). Mind in society: The development of higher psychological processes. Cambridge, MA: Harvard University Press.

Vygotsky, L. (1987). The development of scientific concepts in childhood In R. W. Rieber \& A. S. Carton (Eds.), The collected works of L. S. Vygotsky (Vol. Volume 1 
Problems of general psychology, pp. 167-241). New York: Plenum Press; Kluwer Academic.

Westmacott, A. (2017). Direct vs. indirect written corrective feedback: Student perceptions. Íkala, 22(1), 17-32. http://dx.doi.org/10.17533/udea.ikala.v22n01a02

Yang, M., Badger, R., \& Yu, Z. (2006). A comparative study of peer and teacher feedback in a Chinese EFL writing class. Journal of Second Language Writing, 15(3), 179-200. http://dx.doi.org/10.1016/j.jslw.2006.09.004

Zhang, Z. (2016). Student engagement with computer-generated feedback: a case study. ELT Journal, 71(3), 317-328. doi:10.1093/elt/ccw089

Zheng, Y., \& Yu, S. (2018). Student engagement with teacher written corrective feedback in EFL writing: A case study of Chinese lower-proficiency students. Assessing Writing, 37, 13-24. https://doi.org/10.1016/j.asw.2018.03.001

Zheng, Y., Yu, S., Wang, B., \& Zhang, Y. (2019). Exploring student engagement with supervisor feedback on master's thesis: Insights from a case study. Innovations in Education and Teaching International, 1-12. doi:10.1080/14703297.2019.1617181

Yu, S., \& Jiang, L. (2020). Doctoral students' engagement with journal reviewers' feedback on academic writing. Studies in Continuing Education, 118. doi:10.1080/0158037x.2020.1781610

\section{APPENDIX A}

An example of coding learners' engagement

\begin{tabular}{|c|c|c|}
\hline $\begin{array}{l}\text { Dimensions of } \\
\text { Engagement }\end{array}$ & Category of engagement & Examples of engagement \\
\hline Behavioral & $\begin{array}{l}\text { Performance on /being on the } \\
\text { detecting, correcting, rewriting } \\
\text { tasks }\end{array}$ & $\begin{array}{l}\text { I don't understand this. } \\
\text { Look at the underlined words and phrases } \\
\text { It's ok now. } \\
\text { And is wrong because ... } \\
\text { The classroom has air-conditioner but it doesn't } \\
\text { work ..., seem okay. }\end{array}$ \\
\hline Cognitive & $\begin{array}{l}\text { The extent to which learners } \\
\text { provide clarifications and } \\
\text { explanations, respond to peers' } \\
\text { feedback, and suggest ideas to } \\
\text { process gaps and to rewrite the } \\
\text { texts }\end{array}$ & $\begin{array}{l}\text { I just know to replace learning with facility and } \\
\text { add are not good. } \\
\text { Opposite meaning with the first sentence, use but. } \\
\text { Use because. } \\
\text { It should be "my teacher body was all wet because } \\
\text { the water was splashed". } \\
\text { Look! We need to say reasons to complain. }\end{array}$ \\
\hline Social & $\begin{array}{l}\text { How individuals in and among } \\
\text { groups collaborate with peers to } \\
\text { complete the tasks; listening to } \\
\text { peers' feedback and ideas and } \\
\text { providing feedback and directions } \\
\text { to peers; asking for directions to } \\
\text { process gaps }\end{array}$ & $\begin{array}{l}\text { Why don't you combine the sentences in } \\
\text { paragraph } 2 \text { ? } \\
\text { How? } \\
\text { We need a topic sentence in paragraph } 2 \text {. } \\
\text { I don't think so. } \\
\text { Why not? } \\
\text { Which one? }\end{array}$ \\
\hline
\end{tabular}




\section{APPENDIX B}

Feedback Guide (Dang, 2019; adapted from Yang et al., 2006)

Use the following suggestions to discover gaps and discuss some ways to correct the identified gaps in your pieces of writing in your group. You are encouraged to give more than one solution to treat errors.

\section{Content}

Are ideas relevant to the topic of writing? If you think the ideas are not appropriate, please suggest ideas that are more relevant.

- Are ideas linked? If not, please provide improvements.

- Of the reasons given to support the writer's opinion, which one is or ones are irrelevant to the topic? Highlight the irrelevant arguments and suggest improvements.

Organisation

- Does the writer introduce the topic of the letter or description? Yes/No

- If no, suggest the ideas to introduce the topic of the letter or description.

- If yes, circle it and check a $\sqrt{ }$ after the sentence.

- Is there a topic sentence in each paragraph? Yes/no

- Point out the paragraph without topic sentences. Paragraph.

- Is there a concluding sentence? Yes/no

- If no, suggest a concluding sentence

- If yes, circle it and check a $\sqrt{ }$ after the sentence

Grammar

Use the following suggestions for grammar errors and provide corrections

- Is the use of tense correct?

- If yes, check a $\sqrt{ }$ after the correct tense

- If no, provide corrections

- Does the writer use appropriate conjunctions (i.e., because, although, but) to link ideas?

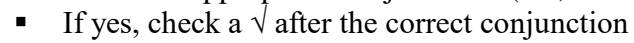

- If no, provide corrections

\section{APPENDIX C}

\section{Example of improved rewritten text of group 8}

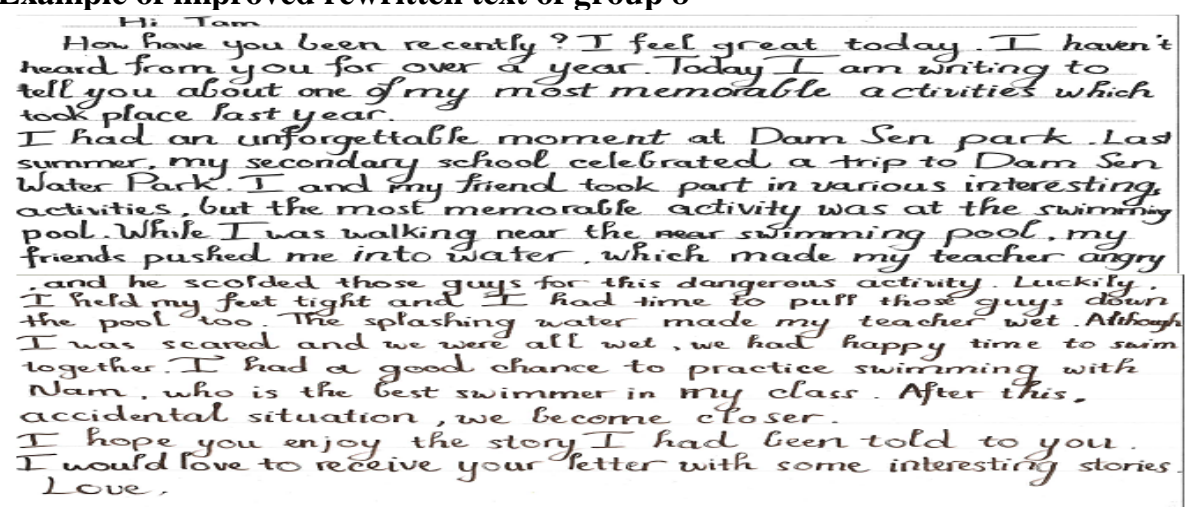

